\title{
A Comparison of FE Analysis of Columns Utilizing Two Stress-Strain Material Relations and Two Different Solvers: ANSYS vs. SCIA Engineer
}

\author{
Daniel Jindra*, Jiř́i Kala* and Zdeněk Kala* \\ * Institute of Structural Mechanics (STM) at the Faculty of Civil Engineering (FCE) of the \\ Brno University of Technology (BUT) \\ Veveří 331/95, 60200 Brno, Czech Republic \\ e-mails: jindra.d@fce.vutbr.cz,kala.j@fce.vutbr.cz,kala.z@fce.vutbr.cz \\ web page: http://www.fce.vutbr.cz
}

\begin{abstract}
Paper presents results of the advanced numerical simulation processes of duplex stainless steel columns. The finite element analyses are conducted utilizing two different implicit solvers: ANSYS Classic technology and the FEM solver implemented in the SCIA Engineer software. Forcedeflection curves along with the ultimate axial load and the corresponding ultimate mid-height lateral deflection of duplex stainless steel (EN grade 1.4462) columns in compression are compared with the results of experimental programme. 9 different column lengths (EN slenderness classes 3 and 4) of circular hollow cross-section (CHS) $88.9 \times 2.6$ have been analysed, and the results are statistically compared.

Two approaches of the material stress-strain relation definition are compared. The first one is in accordance with a behaviour description proposed by Ramberg and Osgood, here utilized as multilinear material model with isotropic hardening and Von Mises yield surface plasticity. The second approach adopts a simplified linear elastic relation up to the $0.2 \%$ proof stress value (the equivalent of the yield strength) and linear plastic behaviour with defined hardening.
\end{abstract}

The difference between results obtained from both numerical solvers (ANSYS and FEM solver within SCIA) are rather negligible and both in a nice match with the experimental data. In order to describe the material behaviour of the stainless steel properly, the stress-strain relation is required to be defined more precisely. The simplified bilinear definition of the stress-strain curve does not seem to be suitable enough to obtain validated results of the numerical analyses.

[1] C. Buchanan, E. Real and L. Gardner, "Testing, simulation and design of cold-formed stainless steel CHS columns.”, Thin-Walled Structures, 130, 297-312 (2018). ISSN: 0263-8231. doi:10.1016/j.tws.2018.05.006.

[2] Ansys, Inc. ANSYS 19.0. Canonsburg, PA 15317 U.S.A., 2018.

[3] Nemetschek Group. SCIA Engineer 20.0. Hasselt 3500 Belgium,2020. 